Review

\title{
Prevention and Treatment of AKI during Various Disasters
}

\author{
Mehmet Sukru Sever $\mathbb{D}^{\mathrm{D}}$
}

Citation: Sever, M.S. Prevention and Treatment of AKI during Various

Disasters. Kidney Dial. 2022, 2, 85-90. https://doi.org/10.3390/

kidneydial2010011

Academic Editor: Roman-Ulrich Müller

Received: 23 January 2022

Accepted: 22 February 2022

Published: 24 February 2022

Publisher's Note: MDPI stays neutral with regard to jurisdictional claims in published maps and institutional affiliations.

Copyright: (c) 2022 by the author Licensee MDPI, Basel, Switzerland. This article is an open access article distributed under the terms and conditions of the Creative Commons Attribution (CC BY) license (https:// creativecommons.org/licenses/by/ $4.0 /)$.
Department of Nephrology, Istanbul School of Medicine, Istanbul University, Istanbul 34093, Turkey; mehmetsukrusever@gmail.com; Tel.: +90-542-513-3809

\begin{abstract}
Acute kidney injury (AKI) is frequent, and shows wide variation with regards to the spectrum, etio-pathogenesis and management strategies after natural (e.g., earthquakes) and manmade disasters (e.g., wars). The most important pathogenetic mechanisms in AKI during earthquakes are crush injury-related hypovolemia and myoglobinuria. Therefore, the most effective preventive measures are early and energetic fluid resuscitation (especially isotonic saline due to medical and logistic advantages) and also avoiding nephrotoxic medications. When preventive measures fail and intrarenal AKI develops, dialysis is lifesaving, with a preference towards intermittent hemodialysis due to medical and logistic advantages during disasters. During wars, the most important man-made disaster, prerenal, intrarenal and postrenal AKI may develop both at the battlefield and also in the field- or tertiary care-hospital setting. Overall, pathogenesis and management strategies of AKI in war victims are similar with those of AKI in general and in natural disasters. Logistic planning after disasters is vital for providing the most effective treatment. If patients cannot be coped with locally, either help should be asked from, or, alternatively, patients should be referred to, other regions or countries. Importantly, nephrology units in and around disaster-prone areas should be prepared for disasters for a sudden influx of AKI victims after disasters.
\end{abstract}

Keywords: acute kidney injury; natural disasters; man-made disasters; crush syndrome; logistic planning

\section{Disasters and AKI}

Management of acute kidney injury (AKI) in disaster victims is problematic because, mostly, patients are complicated, medical infrastructure is damaged and there is a shortage of medical items and personnel [1]. In this review paper, prevention and treatment of AKI in natural and man-made disaster victims will be summarized; however, considering many recent and elegant publications, COVID-19-related AKI will not be dealt with.

\section{Effects of AKI on Outcomes of Disaster Victims}

AKI has diverse systemic consequences on all systems of the body, which include, but are not limited to: fluid retention and consequent respiratory or circulatory failure, persistent systemic inflammation, neurocognitive defects, anemia, acquired immunodeficiency, microvascular injury, thrombosis and, acute respiratory distress syndrome [2]. Furthermore, since many disaster victims also suffer from injuries and related co-morbidities [3], mortality rates may reach up to $41 \%$ in patients who need dialysis support [4].

\section{Prevention and Treatment of AKI during Various Disasters}

\subsection{General Principles}

Prevention and treatment principles for AKI in general are valid for AKI in disaster victims as well. In the 2012 KDIGO AKI guideline, a stage-based management, which considers risk status and stages of AKI, has been suggested [5]. According to this guideline, ensuring volume status and perfusion pressure, monitoring biochemical values, avoiding hyperglycemia and considering alternatives to radiocontrast procedures have been recommended in all stages of AKI. Particularly, in advanced stages, 
taking into account non-invasive and diagnostic workup, checking for changes in drug dosing, considering kidney replacement therapy and ICU admission are mandatory. Finally, if dialysis becomes inevitable, subclavian catheters should be avoided as much as possible [5].

\subsection{Management of AKI during Natural Disasters}

Spectrum, etio-pathogenesis and management of AKI show wide variation in victims of various disasters. Considering the high frequency of AKI during earthquakes, only management of AKI in earthquake victims will be covered.

Mostly, it is assumed that "AKI during earthquakes" terminology refers to crush syndrome. This is a misconception because these victims may suffer from several other types of AKI as well (Figure 1). However, since overall management of non-crushed patients during earthquakes does not differ significantly from AKI due to other etiologies in routine practice, in this paper, mainly, prevention and treatment of crush injury-related AKI will be dealt with.

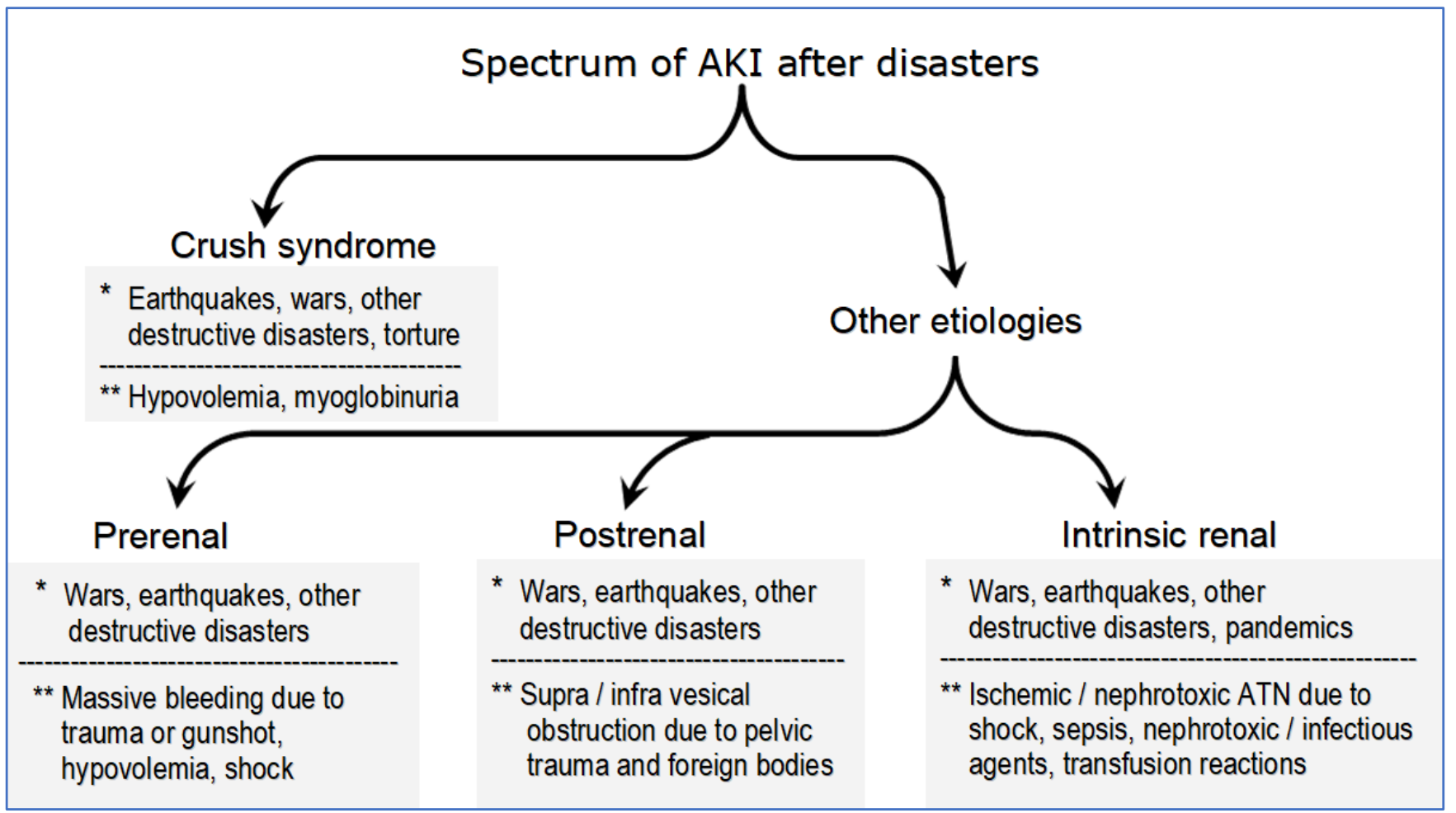

Figure 1. Spectrum of AKI after disasters. Overall, crush syndrome is very common. Similar to routine daily practice, prerenal, intrarenal or postrenal AKI may develop as well in various disasters, with different etio-pathogenetic mechanisms. ${ }^{*}$ Most common disasters are associated with those particular pathologies. These pathologies may also be observed in several other disasters (e.g., volcanoes, mining accidents, hurricanes), albeit less frequently. ${ }^{* *}$ Main pathogenetic mechanisms. (Several other mechanisms may also play a role in the pathogenesis). Abbreviation: ATN: acute tubular necrosis.

Prevention of crush injury-related AKI: In order to understand the rationale of AKIspecific preventive measures, pathogenesis of crush injury-related AKI should be considered. In this complex scenario, traumatic rhabdomyolysis results in dramatic fluid third-spacing (compartment syndrome), leading to intravascular volume depletion, renal hypoperfusion and ischemia. Also, myoglobinuria resulting from extensive muscular trauma causes intratubular cast formation, scavenges nitric oxide and activates inflammatory pathways, all of which can aggravate renal hypoperfusion and tissue injury. Nucleosides released from disintegrating cell nuclei and metabolized to uric 
acid may contribute to cast formation and tubular obstruction as well. Hyperkalemia-, and hyperphosphatemia-induced, hypocalcemia may depress cardiac output potentiating renal hypoperfusion [1]. Among all the above-cited mechanisms, hypoperfusion of the kidneys is the utmost important [6]; therefore, the most effective intervention in prevention of crush-related AKI is early and energetic fluid resuscitation [7]. Fluids should be initiated as soon as possible, ideally even when the victims are still buried under the rubble. Before rescue, fluids should be administered at an infusion rate of $1 \mathrm{~L} / \mathrm{h}$ for adults, 15 to $20 \mathrm{~mL} / \mathrm{kg}$ of body weight per hour for children. Fluids should be continued both during, and also after, extrication. Overall, 3-6 L of fluids are given considering many variables. Afterwards, amount of fluids should be decided considering urine response [8]. This protocol is subject to change depending on many variables including age, body weight, trauma pattern, duration of extrication, urine production, and amount of overall estimated fluid losses as well as ambient temperature and logistic circumstances.

The answer to the question "which fluid?" is multifaceted. All types of fluids have advantages and drawbacks [8]. Theoretically, bicarbonated hypotonic saline is the most ideal fluid, because it is beneficial for preventing hyperkalemia and alkalinizing urine; thus preventing intratubular cast formation. However, due to difficult preparation, usage of this solution is limited in chaotic disaster circumstances. Isotonic saline is the most frequently used solution, which is readily available in disaster conditions, and side effects can be coped with somewhat easily. Hypothetically, mannitol may improve compartment syndrome and renal perfusion, interfere with cast formation and free radical production [9]; although, there are inconsistent reports on its usefulness in traumatic rhabdomyolysis [10].

The efficacy of this early and energetic fluid resuscitation has been nicely shown in the Bingol earthquake, in Turkey, in 2003 [11]. In this disaster, of the 16 crush victims, 14 were receiving isotonic saline on admission to hospitals, which was followed by mannitol-alkaline fluid resuscitation. Duration between rescue and initiation of fluids was significantly shorter in the nondialyzed victims as compared to dialyzed. Also, the volume of administered fluids was significantly higher in the nondialyzed victims, all of who survived [11].

Another very important AKI preventive maneuver in disaster victims is avoiding nephrotoxic medications. However, unfortunately, nonsteroidals and antibiotics with potential nephrotoxicity are frequently used in these victims, who suffer from painful traumatic and surgical wounds and also infections.

Treatment of crush injury-related AKI: When preventive measures fail and full-blown intrinsic renal AKI develops, the only reliable treatment modality is dialysis. Standard clinical and biochemical indications for dialysis are valid for these patients as well. Since hyperkalemia is very frequent and life-threatening, prophylactic dialysis, i.e., dialyzing patients even before appearance of traditional indications, must be considered. All dialysis modalities have both medical and logistic advantages and drawbacks in disaster victims with AKI (Table 1) [12].

In the Marmara earthquake experience, 477 out of 639 crush victims needed dialysis support. Among these, 452 were treated by a single dialysis modality (437 intermittent hemodialysis, 11 continuous renal replacement therapy and 4 peritoneal dialysis), while 25 victims needed more than one type of dialysis. In total, 5137 hemodialysis sessions were performed. Mean number of hemodialysis sessions was 11 and mean duration for dialysis support was 13 days, indicating that many victims received daily dialysis [12]. 
Table 1. Medical and logistic advantages and drawbacks of various dialysis modalities in disaster victims with AKI.

\begin{tabular}{|c|c|c|}
\hline Dialysis Modality & Medical Advantages & Medical Drawbacks \\
\hline IHD & $\begin{array}{l}\text {-High clearance rate of low molecular } \\
\text { weight solutes } \\
\text {-Possibility for dialyzing without } \\
\text { anticoagulation }\end{array}$ & $\begin{array}{l}\text {-Priming volume may induce hypotension } \\
\text {-Risk of disequilibrium syndrome }\end{array}$ \\
\hline CRRT & $\begin{array}{l}\text {-Better volume control } \\
\text {-Lower risk of disequilibrium syndrome } \\
\text {-Administering more calories }\end{array}$ & $\begin{array}{l}\text {-Need for continuous heparinization } \\
\text {-Low removal capacity for small solutes, } \\
\text { like potassium }\end{array}$ \\
\hline PD & $\begin{array}{l}\text {-No need for vascular access } \\
\text {-Less hemodynamic instability }\end{array}$ & $\begin{array}{l}\text {-Low clearance rate } \\
\text {-Difficulty in maintaining sterile technique } \\
\text {-Difficult application in some patients }\end{array}$ \\
\hline & $\begin{array}{c}\text { Logistic Advantages } \\
\end{array}$ & Logistic Drawbacks \\
\hline IHD & $\begin{array}{l}\text {-Possibility to treat several patients per } \\
\text { day at the same position }\end{array}$ & $\begin{array}{l}\text {-Need for experienced personnel and } \\
\text { technical assistance }\end{array}$ \\
\hline CRRT & $\begin{array}{l}\text {-CAVH has the advantage of no need for } \\
\text { pumps and electricity } \\
\text {-Only minimal equipment is needed }\end{array}$ & $\begin{array}{l}\text {-Treatment possibility for only one patient, per } \\
\text { machine per day } \\
\text {-Problematic transportation of fluid bags to the } \\
\text { disaster area }\end{array}$ \\
\hline PD & -No need for water and electricity & $\begin{array}{l}\text {-Problematic transportation of fluid bags to the } \\
\text { disaster area }\end{array}$ \\
\hline
\end{tabular}

Abbreviations: IHD: intermittent hemodialysis, CRRT: continuous renal replacement therapy; PD: peritoneal dialysis, CAVH: continuous arteriovenous hemodiafiltration.

\subsection{Management of AKI during Man-Made Disasters}

Wars, the most important man-made disasters, are characterized by extremely high numbers of casualties [13]. During wars, prerenal, intrarenal and postrenal AKI may develop both at the battlefield and also in the field- or tertiary care-hospital setting. Mostly, massive bleeding resulting from gunshot and/or surgery is responsible from prerenal and consequent ischemic intrinsic renal AKI [14]. In the war victims who are entrapped under the rubble, compartment syndrome and subsequent crush syndrome may result in prerenal and intrarenal AKI as well, whereas urinary tract obstruction may cause post-renal AKI in casualties with pelvic trauma (Figure 1) [14]. AKI in this setting may develop due to nontraumatic etiologies as well; e.g., exposure to chemical and airborne toxins. Overall, victims are characterized by a poor prognosis because of systemic and polytrauma-related complications and suboptimal treatment due to damaged infrastructure and medical/logistic drawbacks.

Terrorist attacks occur suddenly and unexpectedly, affecting hundreds of thousands of civilians, and cause AKI by various mechanisms (e.g., bleeding-related hypotension, exposure to toxic substances, hemoglobinuria, myoglobinuria). However, data about the incidence of AKI during terrorism are very scarce. After 9/11, the collapse of the Twin Towers caused more than 3000 deaths, whereas AKI resulting from crush syndrome was diagnosed in only one case [15].

Other man-made disasters (i.e., traffic accidents, torture) may cause AKI as well [16,17]; whereas, extent of the problem in those particular disasters still needs to be defined.

Overall, management strategies of AKI in victims of man-made disasters are similar with those of AKI in general and in natural disasters; e.g., correcting hypovolemia, avoiding nephrotoxic medications, monitoring serum creatinine and urine output, and others. Importantly, the logistic circumstances significantly affect treatment possibilities, especially during wars. Therefore, transporting casualties from the battlefield initially to field hospitals, and afterward to higher-level healthcare facilities at the earliest convenience, is mandatory [14]. 


\section{Logistic Issues in Management of Disaster Victims with AKI}

Logistics, or "the procurement, maintenance, distribution and replacement of personnel and material," usually is not considered in routine daily practice; whereas, logistic planning after disasters is vital for providing the most effective treatment, because disasters are characterized by chaos and a shortage of medical material and personnel.

It is vital to estimate the extent of potential interventions by defining the magnitude of the problem, the status of healthcare infrastructure, quantity of healthcare personnel and medical material. If there is a possibility of disparity between healthcare demand and supply two options ensue: (1). Asking medical material and personnel help from other regions of the country or from other countries, which was very effectively performed by the Renal Disaster Relief Task Force of the ISN in several past disasters [18] or (2). Alternatively, referral of the AKI patients outside the disaster area may be considered. Importantly, nephrology units in and around disaster-prone areas should develop their own detailed disaster preparedness plans and also action plans, which clarify who will do what, when and how to cope with a sudden influxes of disaster AKI victims [19].

In disaster-prone countries, renal disaster relief coordinators and their substitutes should be assigned and trained in advance on the necessary measures to be taken after the disaster to save as many victims with AKI as possible [19].

\section{Conclusions}

AKI significantly contributes to morbidity and mortality in disaster victims. Management of these patients is considerably more complex than patients in daily life, because of medical and logistic drawbacks. Deaths due to AKI can be decreased by logistic preparations in anticipated disasters, which is vital to offer the best health care to disaster victims with AKI.

Funding: This research received no external funding.

Institutional Review Board Statement: Not applicable.

Informed Consent Statement: Not applicable.

Data Availability Statement: Not applicable.

Conflicts of Interest: The author declares no conflict of interest.

\section{References}

1. Sever, M.S.; Lameire, N.; Van Biesen, W.; Vanholder, R. Disaster nephrology: A new concept for an old problem. Clin. Kidney J. 2015, 8, 300-309. [CrossRef] [PubMed]

2. Kellum, J.A.; Romagnani, P.; Ashuntantang, G.; Ronco, C.; Zarbock, A.; Anders, H.J. Acute kidney injury. Nat. Rev. Dis. Primers 2021, 7, 52. [CrossRef] [PubMed]

3. Sever, M.; Erek, E.; Vanholder, R.; Koc, M.; Yavuz, M.; Aysuna, N.; Ergin, H.; Ataman, R.; Yenicesu, M.; Canbakan, B.; et al. Lessons learned from the catastrophic Marmara earthquake: Factors influencing the final outcome of renal victims. Clin. Nephrol. 2004, 61, 413-421. [CrossRef] [PubMed]

4. Oda, J.; Tanaka, H.; Yoshioka, T.; Iwai, A.; Yamamura, H.; Ishikawa, K.; Matsuoka, T.; Kuwagata, Y.; Hiraide, A.; Shimazu, T.; et al. Analysis of 372 Patients with Crush Syndrome Caused by the Hanshin-Awaji Earthquake. J. Trauma 1997, 42, 470-476, discussion 5-6. [CrossRef]

5. KDIGO AKI Work Group. KDIGO clinical practice guideline for acute kidney injury. Kidney Int. 2012, 2 (Suppl. 2), 1-138.

6. Vanholder, R.; Sever, M.S.; Erek, E.; Lameire, N. Rhabdomyolysis. J. Am. Soc. Nephrol. 2000, 11, 1553-1561. [CrossRef] [PubMed]

7. Better, O.S.; Stein, J.H. Early Management of Shock and Prophylaxis of Acute Renal Failure in Traumatic Rhabdomyolysis. N. Engl. J. Med. 1990, 322, 825-829. [CrossRef] [PubMed]

8. Sever, M.S.; Vanholder, R. Management of Crush Victims in Mass Disasters: Highlights from Recently Published Recommendations. Clin. J. Am. Soc. Nephrol. 2013, 8, 328-335. [CrossRef] [PubMed]

9. Abassi, Z.A.; Hoffman, A.; Better, O.S. Acute renal failure complicating muscle crush injury. Semin. Nephrol. 1998, 18, 558-565. [PubMed]

10. Brown, C.V.; Rhee, P.; Chan, L.; Evans, K.; Demetriades, D.; Velmahos, G.C. Preventing renal failure in patients with rhabdomyolysis: Do bicarbonate and mannitol make a difference? J. Trauma 2004, 56, 1191-1196. [CrossRef] [PubMed] 
11. Gunal, A.I.; Celiker, H.; Dogukan, A.; Ozalp, G.; Kirciman, E.; Simsekli, H.; Gunay, I.; Demircin, M.; Belhan, O.; Yildirim, M.A.; et al. Early and vigorous fluid resuscitation prevents acute renal failure in the crush victims of catastrophic earthquakes. J. Am. Soc. Nephrol. 2004, 15, 1862-1867. [CrossRef] [PubMed]

12. Sever, M.S.; Erek, E.; Vanholder, R.; Yurugen, B.; Kantarci, G.; Yavuz, M.; Ergin, H.; Bozfakioglu, S.; Dalmak, S.; Tulbek, M.Y.; et al. Renal replacement therapies in the aftermath of the catastrophic Marmara earthquake. Kidney Int. 2002, 62, 2264-2271. [CrossRef] [PubMed]

13. Roser, M. War and Peace. 2016. Available online: https:/ / ourworldindata.org/war-and-peace (accessed on 21 February 2022 ).

14. Sever, M.S.; Vanholder, R.; Lameire, N. Acute Kidney Injury in Active Wars and Other Man-Made Disasters. Semin. Nephrol. 2020, 40, 341-353. [CrossRef] [PubMed]

15. Goldfarb, D.S.; Chung, S. The Absence of Rhabdomyolysis-induced Renal Failure Following the World Trade Center Collapse. Am. J. Med. 2002, 113, 260. [CrossRef]

16. Lameire, N.; Vermeersch, E. Nephrological and moral aspects of physical torture. Nephrol. Dial. Transplant. 1995, 10, 160-161. [CrossRef] [PubMed]

17. Santos, P.R.; Monteiro, D.L.S. Acute kidney injury in an intensive care unit of a general hospital with emergency room specializing in trauma: An observational prospective study. BMC Nephrol. 2015, 16, 30. [CrossRef] [PubMed]

18. Vanholder, R.; Sever, M.S.; De Smet, M.; Erek, E.; Lameire, N. Intervention of the Renal Disaster Relief Task Force in the 1999 Marmara, Turkey earthquake. Kidney Int. 2001, 59, 783-791. [CrossRef] [PubMed]

19. Sever, M.S.; Lameire, N.; Vanholder, R. Renal disaster relief: From theory to practice. Nephrol. Dial. Transplant. 2009, 24, 1730-1735. [CrossRef] [PubMed] 